\title{
GLUT12 promotes prostate cancer cell growth and is regulated by androgens and CaMKK2 signaling
}

\author{
Mark A White1,2,*, Efrosini Tsouko1,2,*, Chenchu Lin3,4, Kimal Rajapakshe5, Jeffrey M Spencer1,2, \\ Sandi R Wilkenfeld3,4, Sheiva S Vakili1,2, Thomas L Pulliam1,2,3, Dominik Awad3,4, Fotis Nikolos5, \\ Rajasekhara Reddy Katreddy², Benny Abraham Kaipparettu6,7, Arun Sreekumar5,7, Xiaoliu Zhang1,2, \\ Edwin Cheung 8,9 , Cristian Coarfa ${ }^{5}$ and Daniel E Frigo',2,3,10,11
}

${ }^{1}$ Center for Nuclear Receptors and Cell Signaling, University of Houston, Houston, Texas, USA

2Department of Biology and Biochemistry, University of Houston, Houston, Texas, USA

3Department of Cancer Systems Imaging, The University of Texas M.D. Anderson Cancer Center, Houston, Texas, USA

4The University of Texas MD Anderson Cancer Center UTHealth Graduate School of Biomedical Sciences, Houston, Texas, USA

${ }^{5}$ Department of Molecular and Cellular Biology, Baylor College of Medicine, Houston, Texas, USA

${ }^{6}$ Department of Molecular and Human Genetics, Baylor College of Medicine, Houston, Texas, USA

${ }^{7}$ Dan L. Duncan Cancer Center, Baylor College of Medicine, Houston, Texas, USA

${ }^{8}$ Biology and Pharmacology, Genome Institute of Singapore, A*STAR, Singapore, Singapore

${ }^{9}$ Faculty of Health Sciences, University of Macau, Taipa, Macau, China

${ }^{10}$ Department of Genitourinary Medical Oncology, The University of Texas M.D. Anderson Cancer Center, Houston, Texas, USA

${ }^{11}$ Molecular Medicine Program, The Houston Methodist Research Institute, Houston, Texas, USA

Correspondence should be addressed to D E Frigo: frigo@mdanderson.org

*(M A White and E Tsouko contributed equally to this work)

\begin{abstract}
Despite altered metabolism being an accepted hallmark of cancer, it is still not completely understood which signaling pathways regulate these processes. Given the central role of androgen receptor (AR) signaling in prostate cancer, we hypothesized that AR could promote prostate cancer cell growth in part through increasing glucose uptake via the expression of distinct glucose transporters. Here, we determined that AR directly increased the expression of SLC2A12, the gene that encodes the glucose transporter GLUT12. In support of these findings, gene signatures of AR activity correlated with SLC2A12 expression in multiple clinical cohorts. Functionally, GLUT12 was required for maximal androgenmediated glucose uptake and cell growth in LNCaP and VCaP cells. Knockdown of GLUT12 also decreased the growth of C4-2, 22Rv1 and AR-negative PC-3 cells. This latter observation corresponded with a significant reduction in glucose uptake, indicating that additional signaling mechanisms could augment GLUT12 function in an AR-independent manner. Interestingly, GLUT12 trafficking to the plasma membrane was modulated by calcium/ calmodulin-dependent protein kinase kinase 2 (CaMKK2)-5'-AMP-activated protein kinase (AMPK) signaling, a pathway we previously demonstrated to be a downstream effector of AR. Inhibition of CaMKK2-AMPK signaling decreased GLUT12 translocation to the plasma membrane by inhibiting the phosphorylation of TBC1D4, a known regulator of glucose transport. Further, AR increased TBC1D4 expression. Correspondingly, expression of TBC1D4 correlated with AR activity in prostate cancer patient samples. Taken together, these data demonstrate that prostate cancer cells can increase the functional levels of GLUT12 through multiple mechanisms to promote glucose uptake and subsequent cell growth.
\end{abstract}
Key Words
- GLUT12
- SLC2A12
- glucose metabolism
- androgen receptor (AR)
- calcium/calmodulin- dependent protein kinase kinase 2 (CAMKK2)
- 5'-AMP-activated protein kinase (AMPK)
- prostate cancer 


\section{Introduction}

Altered cell metabolism is now acknowledged as one of the emerging hallmarks of cancer (Hanahan \& Weinberg 2011). Common among most cancer cells is an increased ability to take up and metabolize large amounts of glucose to help meet the growing cells' energetic and anabolic demands. The first rate-limiting step in glucose metabolism is the cellular uptake of the sugars (Hatanaka 1974). This is done primarily by a family of facilitative glucose transporters (GLUTs). To date, fourteen GLUTs have been identified in humans (Barron et al. 2016). While many of these transporters have known functions in basic physiology (ex. GLUT4 functions in muscle), growing evidence indicates roles for some of these transporters in cancer (Luiken et al. 2015, Barron et al. 2016, Labak et al. 2016). To that end, multiple members of the GLUT family are overexpressed in various cancer types (reviewed in (Barron et al. 2016)). Not surprisingly, several oncogenic and tumor suppressive signaling pathways have been shown to regulate glucose uptake (Cairns et al. 2011). The delineation of which specific transporters play a functional role in the disease and the determination of how they are regulated are needed to improve our understanding of this important aspect of pathogenic cell biology.

Prostate cancer is the most commonly diagnosed non-cutaneous cancer in US men (American Cancer Society 2015). One of the central drivers of the disease is the androgen receptor (AR). Despite AR's established role in prostate cancer (Schmidt \& Tindall 2013), our understanding of the specific downstream events that are regulated by AR and that promote the disease is not complete. Recent work from both our laboratory as well as others has demonstrated that androgen signaling increases glucose metabolism (Massie et al. 2011, Moon et al. 2011, Itkonen et al. 2013, Tennakoon et al. 2014, Tsouko et al. 2014). This augmented carbohydrate metabolism was mediated in part through a signaling cascade involving the calcium/calmodulin-dependent protein kinase kinase 2 (CaMKK2) and the 5'-AMPactivated protein kinase (AMPK) (Massie et al. 2011, Tennakoon et al. 2014). Given the requirement for initial glucose uptake prior to its subsequent metabolism, we hypothesized that AR signaling promoted glucose metabolism by increasing the expression and/or activity of select GLUTs in prostate cancer. We further speculated that AR could increase glucose uptake in part through CaMKK2-AMPK signaling. Here, we sought to determine whether androgens increased the expression of any of the GLUTs that were overexpressed in prostate cancers relative to benign tissue. In addition, we wanted to determine the mechanism(s) behind this regulation to aide future efforts to treat the disease.

\section{Materials and methods}

\section{Cell culture and reagents}

LNCaP, C4-2, VCaP, 22Rv1 and PC-3 human prostate cancer cell lines and RWPE-1 immortalized prostate epithelial cells were obtained from American Type Culture Collection (ATCC). LAPC4 cells were a gift from Dr Charles Sawyers (Memorial Sloan-Kettering Cancer Center, New York, NY, USA). Cells were authenticated using shorttandem repeat analysis. Cells were also validated using a PCR-based assay to ensure the cells were free of mycoplasma. All experiments were performed using cells that were $<10$ passages. LNCaP, VCaP, LAPC4, C4-2 and 22Rv1 cells were maintained as previously described (Frigo et al. 2011, Tennakoon et al. 2014, Blessing et al. 2015). RWPE-1 cells were maintained in keratinocyte serum-free medium (K-SFM; contains $1.04 \mathrm{~g} / \mathrm{L}$ D-glucose) supplemented with bovine pituitary extract and human recombinant epidermal growth factor per ATCC's recommendations. PC-3 cells were maintained in RPMI-1640 (Mediatech, Manassas, VA, USA) supplemented with $8 \%$ fetal bovine serum (FBS; Sigma). Prior to all experiments, cells were plated and incubated for $72 \mathrm{~h}$ in media that were phenol-red-free and contained charcoal-stripped FBS (CS-FBS; Gemini Bio-Products, West Sacramento, CA, USA). RWPE-1 cells were switched to phenol-red-free RPMI-1640 medium for experiments.

Methyltrienolone (R1881) was purchased from PerkinElmer. Enzalutamide was from SelleckChem (Houston, TX, USA). STO-609 was purchased from Tocris (Bristol, UK). Anti-AMPK and anti-p-AMPK (T172) antibodies were purchased from Cell Signaling. AntiGLUT12 antibody was purchased from Bioss (Woburn, MA, USA). Anti-TBC1D4, anti-p-TBC1D4 (T642), anti-ATPase antibodies and the Plasma Membrane Protein Extraction Kit were purchased from Abcam. Mission siRNAs targeting SLC2A12 (GLUT12) and TBC1D4, universal siRNA-negative control and anti-GAPDH antibody were purchased from Sigma-Aldrich. Stealth siRNAs targeting control or AMPK were purchased from Thermo Fisher Scientific. Anti-AR antibody was purchased from Santa Cruz Biotechnology. 


\section{RNA isolation, CDNA synthesis and quantitative PCR ( $q P C R$ )}

RNA isolation, cDNA preparation and qPCR were carried out as previously described using $R P L P 0 / 36 \mathrm{~B} 4$ as an internal control (Frigo et al. 2011). All primers used in this study are listed in Supplementary Table 1 (see section on supplementary data given at the end of this article).

\section{Immunoblot analysis}

Immunoblot analysis was performed as previously described (Tennakoon et al. 2014). All antibodies were used at the manufacturers' recommended concentrations. Results shown are representative blots. Densitometry was performed using ImageJ software (National Institutes of Health (NIH)), and samples were normalized to indicated controls. Results are presented as normalized mean values+S.E.M. from experimental repeats $(n \geq 3)$.

\section{Bioinformatic analyses of gene expression in clinical datasets}

For the gene expression signature comparisons, transcriptomic profiles of human prostate cancer cohorts were downloaded from GEO (GSE21034, Taylor et al. (2010); GSE35988, Grasso et al. (2012)) or The Cancer Genome Atlas (TCGA). Androgen-induced signatures (Hieronymus AR and Nelson AR) were generated from previously defined data (Nelson et al. 2002, Hieronymus et al. 2006). For each of the signatures, an activity score for each sample in each cohort was generated as described previously (Taylor et al. 2010). Briefly, gene expressions of prostate cancer cohorts were converted to $z$ scores with respect to normal samples. The activity score for each sample for a signature was evaluated by adding the $z$ scores of upregulated genes and subtracting the $z$ scores of downregulated genes. Correlation between pairs of gene signature activity scores were evaluated using the Pearson correlation coefficient as implemented in the Python statistical library SciPy; significance was assessed at $P<0.05$.

\section{RNAi transfection}

Transient transfections of siRNAs were performed as previously described (Blessing et al. 2015) with the lone exception that PC-3 cells were transfected twice $24 \mathrm{~h}$ apart with siRNAs to achieve sufficient knockdown. The sequences of the siRNAs are listed in Supplementary Table 1.

\section{Proliferation assay}

Cell proliferation assays were carried out as previously described by measuring the cellular double-stranded DNA content using a fluorescent DNA stain (Shi et al. 2013).

\section{Glucose uptake assay}

LNCaP, VCaP or RWPE- 1 cells were plated at a density of $2.5 \times 10^{5}$ cells per well in a 6 -well plate while PC-3 cells were plated at a density of $1.5 \times 10^{5}$ cells per well in a 6-well plate. Cells were transfected and treated (LNCaP, VCaP and RWPE- 1 cells only) for $24 \mathrm{~h} \pm 10 \mathrm{nM}$ R1881 in starvation medium (phenol-red free RPMI-1640 medium alone containing $2 \mathrm{~g} / \mathrm{L}$ D-glucose with $10 \mathrm{mM}$ HEPES (Sigma) and 0.1\% bovine serum albumin (BSA; Sigma)). Afterward, medium was switched to phenol-red-free RPMI-1640 medium (LNCaP, VCaP, PC-3) or K-SFM (RWPE-1) for $2 \mathrm{~h}$. The medium was then collected and analyzed using an YSI 2700 Bioanalyzer (YSI Life Sciences, Yellow Springs, OH, USA). Glucose uptake levels were normalized to cellular DNA amounts.

\section{Chromatin immunoprecipitation sequencing (ChIP-Seq)}

ChIP-Seq analysis was performed as previously described (Chng et al. 2012, Tan et al. 2012).

\section{Reporter gene assays}

Cells were transfected with plasmids using Lipofectamine 2000 (ThermoFisher Scientific) according to the manufacturer's instructions and then treated with hormones approximately $16 \mathrm{~h}$ before the assay. Luciferase and $\beta$-galactosidase (transfection normalization) activities were measured as previously described (Blessing etal. 2015). Each treatment was performed in triplicate, and results are expressed as mean relative light units (RLUs) normalized to $\beta$-galactosidase transfection control+s.E. Each experiment was repeated at least 3 times with a representative experiment shown. The pGL4.26-SLC2A12 (SLC2A12-Luc) enhancer construct was created by PCR amplifying the sequence (forward primer: 5'-CAGTCGGTACCTACCC CTCCTGGATTCTAAAT-3'; reverse primer: 5'-CGAGGCTCGAGCTTTAC ATCCATATTCACATT-3') that encompassed the potential AR-binding site identified using ChIP-Seq (Chng et al. 2012, Tan et al. 2012) and shown in Supplementary Fig. 6 that was located within intron 2 of SLC2A12. This fragment (c) 2018 Society for Endocrinology Published by Bioscientifica Ltd. Printed in Great Britain 
was then cloned into the pGL4.26 vector (Promega) using KpnI and XhoI restriction sites. The ARE deletion plasmids were generated by overlap extension PCR. Primary DNA fragments were amplified from full-length enhancer PCRs generated above using Hot Start Phusion polymerase (NEB, Ipswich, MA, USA) and deletion primers (ARE-1 deletion, forward primer: 5'-GTGTAAATAGAGGTA TGAAGGAAAAAAGTAACATTGAAAGCAAGATTAA-3', reverse primer: 5'-TTAATCTTGCTTTCAATGTTACTTTTT TCCTTCATACCTCTATTTACAC-3'; ARE-2 deletion, forward primer: 5'-TGGAGTTTAAAGAAGATTTTTATTATACC AGATCTTGAATGCATTAC-3', reverse primer: 5'-GTAA T G C A T T C A A G A T C T G G T A T A A T A A A A A TCTTCTTTAAACTCCA-3') combined with the above primers in the appropriate pairs to generate single or double deletions. The resulting PCR products were purified and eluted into $10 \mu \mathrm{L}$ water with a Zymo Clean and Concentrator Kit (Irvine, CA, USA) following the manufacturer's instructions. Full-length deletion fragments were generated in a second PCR by mixing $2 \mu \mathrm{L}$ of the appropriate 2 or 3 purified fragments to produce the desired deletion mutants. The resulting products were subsequently purified and cloned using the same procedure as the full-length enhancer. All sequences were confirmed using restriction digests and sequencing. The KLK3 (PSA)-Luc reporter plasmid was previously described (Frigo et al. 2011).

\section{Creation of stable cell lines}

LNCaP cells that stably express CAMKK2 under the control of a doxycycline-inducible promoter were made by first creating a pINDUCER20-CAMKK2 lentiviral construct using the Gateway recombinase cloning system. To do this, the CAMKK2-coding sequence was shuttled from pOTB7-CAMKK2 (American Type Tissue Culture) to pINDUCER20 (gift from Thomas Westbrook). LNCaP cells were then infected with lentivirus expressing pINDUCER20-CAMKK2, and cells were selected using G418 (Sigma).

22Rv1 cells that stably express an shRNA targeting CAMKK2 under the control of a doxycycline-inducible promoter were made by first creating a pINDUCER10shCAMKK2 lentiviral construct via subcloning an shRNA targeting CAMKK2 from pGIPZ-shCAMKK2 (Baylor College of Medicine C-BASS Core) into pINDUCER10 (gift from Thomas Westbrook) using XhoI and MluI restriction sites. 22Rv1 cells were then infected with lentivirus-expressing pINDUCER10-shCAMKK2, and cells were selected using puromycin (Sigma).

\section{Plasma membrane fractionation}

Cells were plated at a density of $6 \times 10^{6}$ cells per $45 \times 120 \mathrm{~mm}$ dish. Three dishes were used per treatment group to total $18 \times 10^{6}$ cells. Cells were then transfected with siRNAs and/or treated as indicated. After transfection/treatment, cells were harvested for whole-cell lysates or plasma membrane subcellular fractionation. The fractionation was performed according to manufacturer's instructions (Abcam). Protein levels were determined using immunoblot analysis.

\section{Statistical analysis}

Unless otherwise noted, two-sample comparisons were performed using Student's $t$ tests. Multiple comparisons were performed using one-way ANOVA and post hoc Dunnett's test with GraphPad Prism, version 5 (GraphPad Software). Statistically significant changes were determined at the $P<0.05$ level.

\section{Results}

\section{Identification of SLC2A12 as a direct AR-regulated gene that is overexpressed in prostate cancer}

We first sought to determine if AR signaling, a major driver of prostate cancer (Schmidt \& Tindall 2013), increased the expression of members of the GLUT family. To test this, AR+ LNCaP prostate cancer cells were treated for 24 or $72 \mathrm{~h}$ with vehicle or the synthetic androgen R1881. Cells were then lysed and subjected to qRT-PCR analysis to quantitate the mRNA levels of the 14 known GLUT family members. Of the 14 members, only two (SLC2A2 (GLUT2) and SLC2A14 (GLUT14)) could not be detected at the mRNA level (Fig. 1A). Three family members (SLC2A3 (GLUT3), SLC2A10 (GLUT10) and SLC2A12 (GLUT12)) were found to be androgen responsive (Fig. 1A). While androgen treatment increased SLC2A3 mRNA levels, this observation did not correspond to an increase in the functional protein levels of GLUT3 as siRNA-mediated knockdown of SLC2A3 had no effect on androgen-mediated glucose uptake (D Frigo, unpublished observations). These data are consistent with previous reports of high SLC2A3 mRNA levels being detected in the absence of GLUT3 protein expression (Simpson et al. 2008). Like SLC2A3, androgens also increased the mRNA levels of SLC2A10 twofold (Fig. 1A). However, the baseline mRNA levels of SLC2A10 were low (Ct values 31-32 cycles) and, more importantly, SLC2A10 expression did 
not correlate with prostate cancer in clinical samples (Welsh et al. 2001, Vanaja et al. 2003, Varambally et al. 2005, Taylor et al. 2010, Grasso et al. 2012). Conversely, androgens increased the expression of SLC2A12 (Fig. 1A), the expression of which was also significantly elevated in prostate cancer patient samples relative to benign controls in multiple clinical cohorts (Table 1) (Welsh et al. 2001, Vanaja et al. 2003, Varambally et al. 2005, Taylor et al. 2010, Grasso et al. 2012). Consistent with these findings, androgen treatment increased the expression of SLC2A12 in additional AR+ prostate cancer cell models (LAPC4 and VCaP; Supplementary Fig. 1). Androgens also increased the protein levels of GLUT12 in multiple cell models (Fig. 1B). Conversely, we were unable to detect GLUT12 in non-transformed RWPE-1 prostate epithelial cells (Supplementary Fig. 2). Further analysis indicated that the peak androgen-mediated expression of GLUT12 in prostate cancer cells occurred $\sim 24 \mathrm{~h}$ after initial treatment (Fig. 1C), indicating that androgens promoted a pulse of GLUT12 synthesis. To assess whether AR could also regulate $S L C 2 A 12$ in patients, we leveraged a previously published, curated AR gene signature of identified AR target genes (genes that were increased in response to androgens and modulated by AR antagonists) (Hieronymus et al. 2006). Using an informatics approach, we determined that this AR gene signature positively correlated with increased SLC2A12 mRNA transcript levels in a well-known clinical prostate cancer cohort (Fig. 1D), suggesting AR also regulates the expression of SLC2A12 in patients (Taylor et al. 2010). In support of this, similar results were obtained using this AR activity signature as well as an additional AR activity signature (Nelson et al. 2002)
A

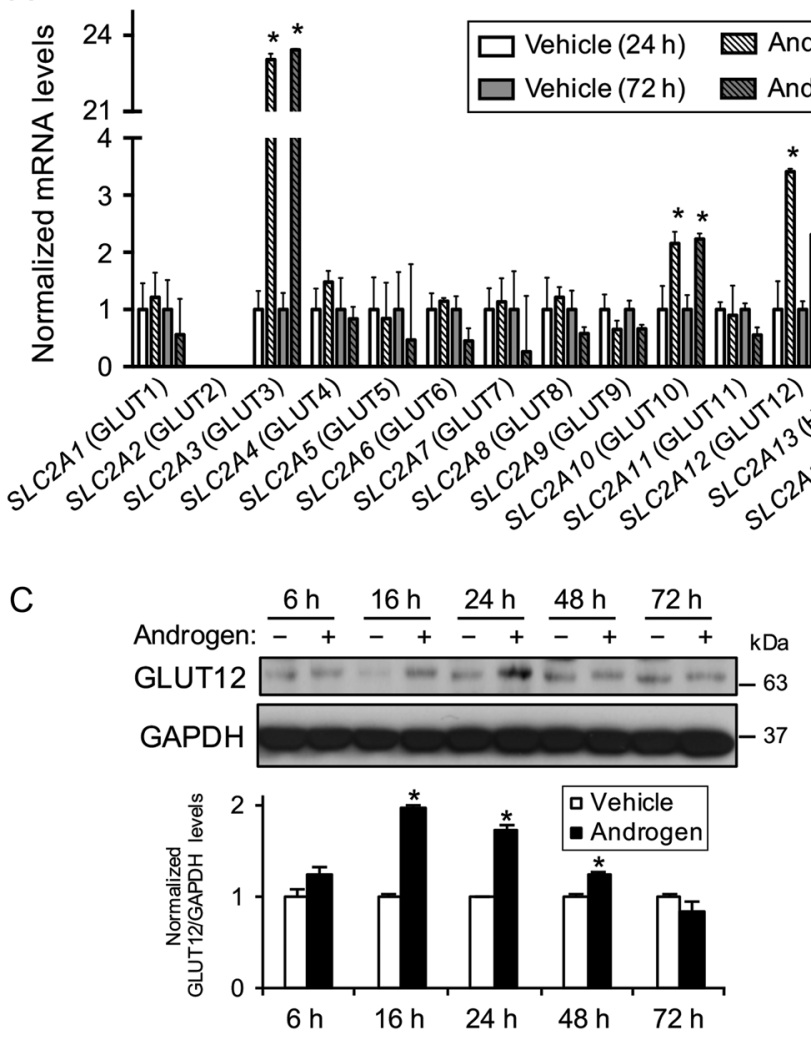

B

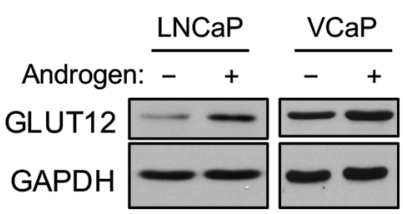

\section{Figure 1}

Identification of SLC2A12 (GLUT12) as an AR-regulated gene in prostate cancer. (A) LNCaP cells were treated \pm androgen (10 nM R1881) for 24 or $72 \mathrm{~h}$. Total RNA was then extracted and subjected to qRT-PCR analysis to detect the mRNA levels of indicated glucose transporters. Data were normalized to 36B4 (RPLPO) levels. *Significant $(P<0.05)$ changes from vehicle treatment. (B) Indicated cells were treated \pm androgen $(10 \mathrm{nM} \mathrm{R} 1881)$ for $16 \mathrm{~h}$. Whole cell lysates were then extracted and analyzed via Western blot. GAPDH was used as a loading control. (C) LNCaP cells were treated \pm androgen (10 nM R1881) for indicated time points. Whole cell lysates were then extracted and analyzed via Western blot. GAPDH was used as a loading control. Top, representative images. Bottom, densitometry analysis $(n=3)$. (D) Expression of SLC2A12 correlated significantly with a previously described AR gene signature (Hieronymus et al. 2006) in transcriptomic profiles of prostate cancer patients from the Taylor et al. (2010) prostate cancer clinical cohort. Similar results were obtained using this AR activity signature as well as an additional AR activity signature (Nelson et al. 2002) across multiple clinical cohorts (Taylor et al. 2010, Grasso et al. 2012) including The Cancer Genome Atlas (TCGA) (Cerami et al. 2012). 
Table 1 Fold increased expression of SLC2A12, the gene that codes for GLUT12 and TBC1D4 in prostate cancer samples compared to benign controls in clinical datasets.

\begin{tabular}{|c|c|c|c|c|}
\hline Gene & Dataset & $\begin{array}{l}\text { \# of } \\
\text { samples }\end{array}$ & $\begin{array}{l}\text { Fold } \\
\text { change }\end{array}$ & $P$ value \\
\hline \multirow[t]{5}{*}{$\overline{S L C 2 A 12}$} & Welsh et al. (2001) & 34 & 1.516 & $3.05 E-5$ \\
\hline & $\begin{array}{l}\text { Varambally et al. } \\
(2005)\end{array}$ & 19 & 1.559 & 0.020 \\
\hline & Taylor et al. (2010) & 185 & 1.294 & 0.008 \\
\hline & Grasso et al. (2012) & 122 & 1.448 & 0.007 \\
\hline & Vanaja et al. (2003) & 40 & 1.315 & 0.039 \\
\hline \multirow[t]{7}{*}{$T B C 1 D 4$} & $\begin{array}{l}\text { Varambally et al. } \\
(2005)\end{array}$ & 19 & 2.58 & $1.54 \mathrm{E}-4$ \\
\hline & Wallace et al. (2008) & 89 & 1.837 & $2.95 \mathrm{E}-4$ \\
\hline & Grasso et al. (2012) & 122 & 1.864 & $1.35 \mathrm{E}-7$ \\
\hline & Vanaja et al. (2003) & 40 & 1.524 & $3.38 \mathrm{E}-5$ \\
\hline & Welsh et al. (2001) & 34 & 2.24 & $1.78 \mathrm{E}-4$ \\
\hline & Taylor et al. (2010) & 185 & 1.467 & $8.65 E-6$ \\
\hline & Luo et al. (2002) & 30 & 1.495 & 0.018 \\
\hline
\end{tabular}

across multiple clinical cohorts (Taylor et al. 2010, Grasso et al. 2012) including The Cancer Genome Atlas (TCGA) (Cerami et al. 2012). As a comparison, AR activity did not correlate with the expression of other genes such as GAPDH and TGFB1 and inversely correlated with GLRA2 and CD200 (Supplementary Fig. 3), two genes previously demonstrated to be downregulated by AR (Hieronymus et al. 2006).

To determine how androgens increased SLC2A12 expression, we first evaluated the role of AR to verify that this was a receptor-mediated event. Knockdown of $A R$ using two separate, validated siRNAs (Tsouko et al. 2014, Blessing et al. 2015, 2017) blocked the androgenmediated expression of $S L C 2 A 12$ (Fig. 2A). As further validation, co-treatment of prostate cancer cells with the antiandrogen enzalutamide suppressed androgenmediated SLC2A12 expression (Fig. 2B and Supplementary Fig. 4). Enzalutamide's inhibition of androgen-mediated SLC2A12 expression was overcome by saturating concentrations of the agonist, confirming AR's role (Fig. 2B).

Androgen treatment increased SLC2A12 mRNA expression as early as $6 \mathrm{~h}$ after treatment (Supplementary Fig. 5), suggesting that SLC2A12 could be a direct AR target gene. Hence, we next wanted to determine whether SLC2A12 was a direct AR target. To do this, we initially co-treated prostate cancer cells \pm androgen in the presence or absence of cycloheximide, an inhibitor of translation (Fig. 2C). As previously described, cycloheximide treatment did not block androgen induction of FKBP5, an established direct target of AR (Frigo et al. 2009, Blessing et al. 2017). Conversely, cycloheximide did inhibit the androgen-mediated expression of CXCR4, a known indirect target of AR (Frigo et al. 2009). Similar to FKBP5, cycloheximide treatment did not impair the androgenmediated expression of SLC2A12 (Fig. 2C), suggesting that SLC2A12 was also a direct AR target. Mining of existing chromatin-immunoprecipitation sequencing (ChIP-Seq) datasets from several prostate cancer cell models indicated that AR directly bound to an intronic region of SLC2A12 in the presence of dihydrotestosterone (DHT) (Fig. 2D and Supplementary Fig. 6) (Chng et al. 2012, Tan et al. 2012). To confirm that the identified AR-binding region contained a functional androgen response element (ARE) and thus primary AR target, we cloned out the genomic region surrounding the identified binding site and tested its ability to confer androgen responsiveness to an enhancerless luciferase reporter gene. While not as robust as the well-known KLK3 ARE, the identified SLC2A12 AR-binding site indeed conferred androgen responsiveness, indicating that $S L C 2 A 12$ was also a direct AR target (Fig. 2E). Further, we identified two potential AREs (ARE 1: AGTACT TGC TGTTCT; ARE 2: GGAACA AGC TTTTCA) within this region that bore resemblance to the consensus ARE sequence: AGAACA NNN TGTTCT. We then deleted both of these AREs alone or in combination from the full-length SLC2A12 enhancer construct and found that loss of either element was sufficient to ablate androgen induction, confirming this site to be a direct AR target (Fig. 2E).

\section{GLUT12 is required for maximal glucose uptake and cell growth in prostate cancer cells}

To investigate the functional importance of GLUT12, we depleted GLUT12 levels using siRNAs in diverse prostate cancer cell models (Fig. 3A). Interestingly, GLUT12 was still expressed in the AR-negative PC-3 cells, suggesting that in this aggressive prostate cancer model, additional, AR-independent mechanisms maintain GLUT12 expression. GLUT12 knockdown blocked androgenmediated glucose uptake (Fig. 3B) and proliferation (Fig. 3C) in LNCaP and VCaP cells. Knockdown of GLUT12 also decreased glucose uptake (Fig. 3B) and proliferation (Fig. 3C) in PC-3 cells. These effects were not unique to LNCaP, VCaP and PC-3 cells as GLUT12 knockdown impaired the growth of additional castration-resistant prostate cancer (CRPC) cell models including C4-2 and 22Rv1 (Fig. 3C). Collectively, these results demonstrate that GLUT12 is required for maximal androgen-mediated glucose uptake and cell growth in hormone-sensitive prostate cancer cells and may also be required for basal glucose uptake and cell growth in some CRPC cell models. 
B
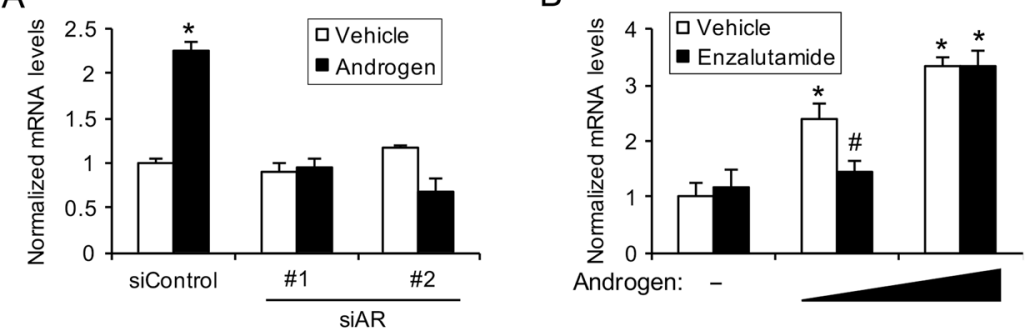

C
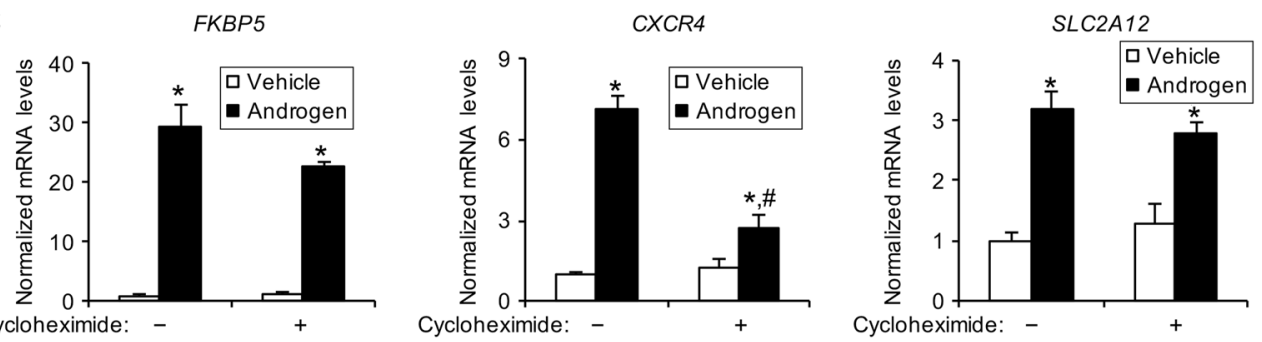

D
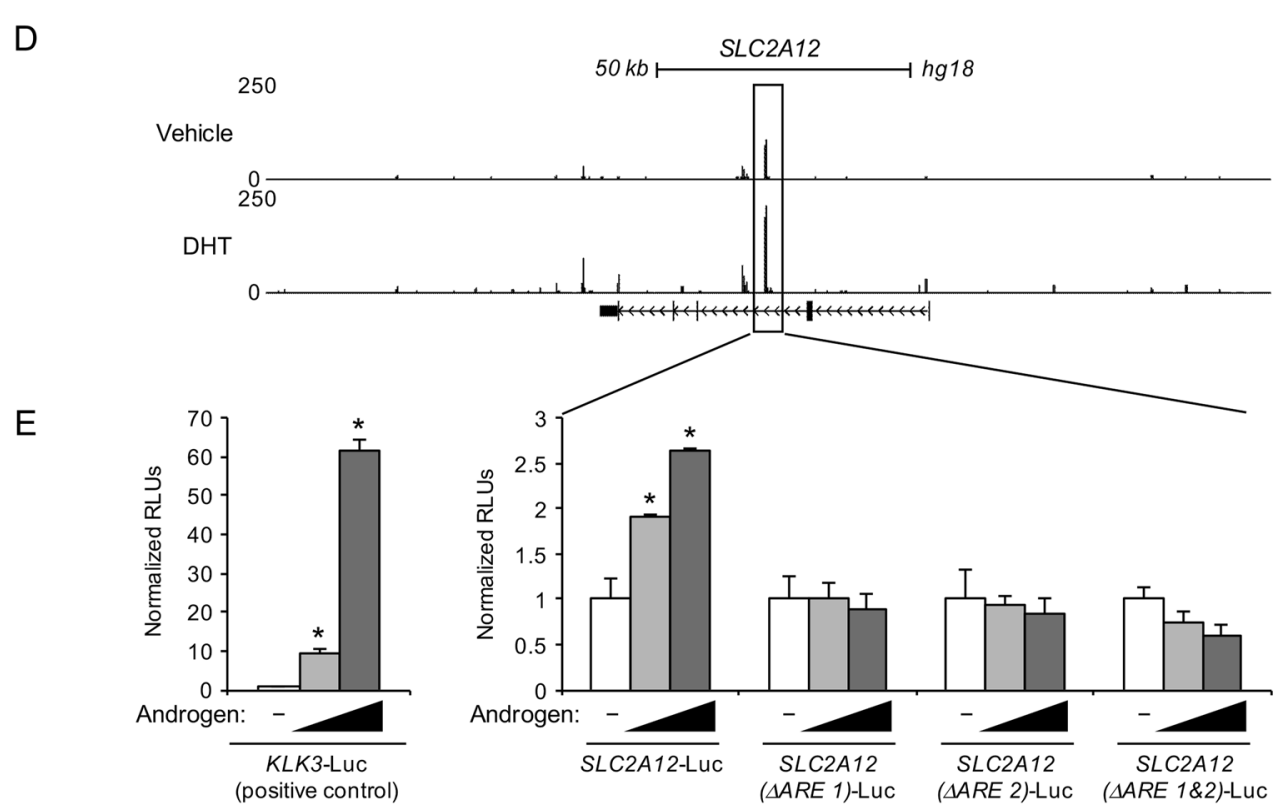

Figure 2

SLC2A12 is a direct AR target. (A) LNCaP cells were transfected with siRNAs targeting a scramble sequence (siControl) or $A R$ and then treated \pm androgen $(10 \mathrm{nM}$ R1881) for $72 \mathrm{~h}$. SLC2A12 relative mRNA expression was quantified via qRT-PCR and data were normalized to $36 \mathrm{~B} 4$ levels. *Significant $(P<0.05)$ changes from vehicle treatment. (B) LNCaP cells were co-treated $\pm 10 \mu \mathrm{M}$ enzalutamide (antiandrogen) with increasing concentrations of androgen ( 0 , $100 \mathrm{pM}$ or $10 \mathrm{nM}$ R1881) for $72 \mathrm{~h}$. SLC2A12 mRNA levels were quantified using qRT-PCR and normalized to 36B4 levels. *Significant ( $P<0.05)$ changes from vehicle (no androgen) treatment. \#Significant $(P<0.05)$ changes from vehicle (no enzalutamide) treatment. (C) LNCaP cells were treated for $16 \mathrm{~h} \pm 1 \mu \mathrm{g} / \mu \mathrm{L}$ cycloheximide \pm androgen (10 nM R1881). FKBP5 is a direct transcriptional target of AR (Frigo et al. 2009). CXCR4 is an indirect transcriptional target of AR (Frigo et al. 2009). Data are normalized to 36B4 levels. *Significant $(P<0.05)$ changes from double vehicle. (D) ChIP-Seq tracks of LNCaP cells treated with vehicle or DHT for $2 \mathrm{~h}$. An AR binding site located within an intronic region of SLC2A12 is highlighted. Similar data for VCaP and C4-2B cells are presented in Supplementary Fig. 6. (E) Enhancer luciferase reporter constructs including a known enhancer of the $K L K 3$ (PSA) gene (left graph; positive control) or the AR-binding region identified in (D) with intact or candidate AREs deleted (right graphs) were transfected into LNCaP cells and treated overnight with $0,0.1$ or $10 \mathrm{nM}$ androgen (R1881). After treatment, cells were harvested and assayed for luciferase activity. Luciferase values were normalized to the $\beta$-galactosidase transfection control. Data are the mean relative light units (RLUs) \pm s.E.M. for one representative experiment conducted in triplicate $(n=3)$. *Significant $(P<0.05)$ changes from vehicle-treated cells. 


\section{TBC1D4 is regulated by AR and} CaMKK2-AMPK signaling

While SLC2A12 is a direct AR target, the activity of several GLUTs can be controlled by additional regulatory mechanisms (Barron et al. 2016). Previous work from our laboratory and others demonstrated that androgens increased glucose metabolism and prostate cancer cell growth in part through a CaMKK2-AMPKmediated mechanism (Massie et al. 2011, Tennakoon et al. 2014). Accordingly, inhibition of CaMKK2 using the antagonist STO-609 or depletion of AMPK using siRNAs (Supplementary Fig. 7) decreased androgenmediated LNCaP prostate cancer cell growth (Fig. 4A and B) and basal cell growth in AR-negative PC-3 cells (Supplementary Fig. 8A and B). This occurred in LNCaP cells despite the fact that knockdown of AMPK led to an increase in AR (perhaps as a compensatory survival mechanism) (Supplementary Fig. 7), consistent with the work of others suggesting that AMPK may feedback to inhibit AR under certain contexts (Jurmeister et al. 2014, Shen et al. 2014). In contrast, STO-609 appeared to decrease basal AR levels (Fig. 4C), matching previous reports that indicated CaMKK2 signaling could augment AR activity (Karacosta et al. 2012, 2016). However, this effect was lost in the presence of androgens. Of interest, AMPK has been shown to promote glucose uptake through the phosphorylation and regulation of tre-2/USP6, BUB2, cdc16 domain family member 4 (TBC1D4; also called Akt substrate of $160 \mathrm{kDa}$ (AS160)), a protein that controls the trafficking of GLUT-containing vesicles (Kramer et al. 2006, Treebak et al. 2006). To determine whether this regulation also occurred in prostate cancer, we treated cells \pm STO- $609 \pm$ androgen and quantified the levels of T642 phosphorylated TBC1D4 (known AMPK target site (Kramer et al. 2006, Treebak et al. 2006)). As predicted, androgens increased AMPK signaling and p-TBC1D4 levels, an effect that was inhibited by STO-609 (Fig. 4C). Surprisingly, androgens also increased the total protein levels of TBC1D4 (relative to GAPDH loading control) in a CaMKK2-dependent manner (Fig. 4C), a CaMKK2mediated effect that was also observed in PC-3 cells (Supplementary Fig. 8C). This was of further importance because the expression of TBC1D4 was elevated in samples from prostate cancer patients in multiple clinical cohorts (Table 1) (Welsh et al. 2001, Luo et al. 2002, Vanaja et al. 2003, Varambally et al. 2005, Wallace et al. 2008, Taylor et al. 2010, Grasso et al. 2012). To verify the effects on TBC1D4 expression, we created stable LNCaP derivatives that could inducibly overexpress $C A M K K 2$, and thus, increase AMPK signaling, in the presence of doxycycline (Fig. 4D, E and Supplementary Fig. 9). Here, expression of CAMKK2 was sufficient to increase AMPK activity as previously described (Frigo et al. 2011). In addition, CAMKK2 expression increased the T642 phosphorylation of TBC1D4 (relative to total TBC1D4) and increased the total levels of TBC1D4 (relative to GAPDH loading control) (Fig. 4E). However, it should be noted that the CaMKK2-mediated increase in TBC1D4 levels was more moderate than that with androgen treatment (Fig. 4E), suggesting that additional AR-regulated pathways likely also govern TBC1D4 expression.

To confirm AR's role in TBC1D4 expression, we depleted AR using siRNAs to demonstrate that $A R$ was required for both basal and androgen-mediated TBC1D4 expression (Fig. 4F). Additionally, treatment of LNCaP cells with androgens increased TBC1D4 mRNA levels (Supplementary Fig. 9). In support of these data, the AR antagonist enzalutamide decreased androgen-mediated TBC1D4 mRNA and TBC1D4 protein expression (Supplementary Fig. 10). However, overexpression of CAMKK2 alone was not sufficient to increase TBC1D4 mRNA levels (Supplementary Fig. 9), implying that CaMKK2's effects on TBC1D4 levels are at the posttranscriptional level. Finally, we determined that AR gene signatures (Fig. 4G) positively correlated with TBC1D4 mRNA levels in multiple clinical cohorts (Taylor et al. 2010, Grasso et al. 2012) including TCGA (Cerami et al. 2012). Taken together, these data indicate that AR and CaMKK2 signaling can increase the expression and activity of TBC1D4 through separate mechanisms.

\section{TBC1D4 regulates glucose uptake via GLUT12 trafficking to the plasma membrane}

Given TBC1D4's known role in glucose uptake, we next wanted to test its functional role in prostate cancer cells. To test this, we depleted TBC1D4 levels using siRNAs (Fig. 5A) to impair TBC1D4-mediated vesicle trafficking. Knockdown of TBC1D4 blocked androgenmediated glucose uptake in $\mathrm{LNCaP}$ and $\mathrm{VCaP}$ cells and basal glucose uptake in PC-3 cells (Fig. 5B). The impaired glucose uptake corresponded with decreased cell growth (Fig. 5C). Interestingly, while androgens also increased TBC1D4 protein levels in non-transformed RWPE-1 cells, knockdown of TBC1D4 did not translate to significant effects on glucose uptake or cell growth (Supplementary Fig. 11), suggesting that TBC1D4-mediated glucose uptake may be more selectively used by cancer cells. We next 
assessed the role of TBC1D4 in GLUT12 translocation to the plasma membrane. To do this, we depleted TBC1D4 using siRNA, treated cells \pm androgen (AR+ LNCaP and VCaP cells only) and collected protein from whole cell lysates (WCL) or following isolation of the plasma membrane fraction (PM). Knockdown of TBC1D4 did not affect the total levels of GLUT12 (WCL samples), but did decrease GLUT12 in the plasma membrane fraction (PM samples) (Fig. 5D). These results indicated that TBC1D4 was required for maximal GLUT12 PM localization. Consistent with a role for CaMKK2 signaling in this process, treatment with the CaMKK2 inhibitor STO-609 blocked the expression of GLUT12 specifically at the PM (Supplementary Fig. 12). Due to concerns regarding potential off-target effects of STO-609, we decided to complement our pharmacological experiments with a molecular approach. First, we utilized our LNCaP-CAMKK2 stable cells (Fig. 4D and E) to demonstrate that, similar to androgen treatment, overexpression of CAMKK2 alone was sufficient to increase GLUT12 levels in the PM fraction (Supplementary Fig. 13). However, despite multiple attempts, we were unable to obtain a PM fraction from these cells that was completely devoid of GAPDH or CaMKK2. While previous work has indicated (1) AMPK signaling at the PM (Miyamoto et al. 2015 and Supplementary Fig. 13), and therefore, possibly CaMKK2 and (2) GAPDH localization to the plasma membrane (Sirover 2012, Seidler 2013), we could not exclude the possibility that the increased GLUT12 levels we observed in the PM fractions derived from the doxycycline-treated samples were due to incomplete fractionation. Thus, we also decided to assess GLUT12 levels following the knockdown of CAMKK2. To do this, we created stable cells that could overexpress an shRNA targeting CAMKK2, and therefore decrease AMPK signaling, in the presence of doxycycline (Fig. 5E). Initial attempts to create LNCaP-shCAMKK2 cells were unsuccessful (could not achieve significant doxycycline-mediated knockdown) and so we created stable derivatives of the CRPC 22Rv1 cells, which we have found to be more amenable to lentiviral manipulations (D Frigo, unpublished observations). Here, CaMKK2 signaling was decreased following $72 \mathrm{~h}$ of doxycycline treatment (Fig. 5E). Correspondingly, PM GLUT12 levels were also decreased (Fig. 5F). Interestingly, in this model, silencing CaMKK2 also led to a decrease in overall GLUT12 levels, suggesting that impairing GLUT12 trafficking could destabilize the protein in some cell contexts. In support of this finding, overexpression of CAMKK2 alone increased total GLUT12 protein levels (Supplementary Fig. 13). Surprisingly, while androgens increased GLUT12 trafficking to the $\mathrm{PM}$ in VCaP and LNCaP-CAMKK2 cells (Fig. 5D and Supplementary Fig. 13), androgen treatment did not result in an increased level of GLUT12 at the PM in our parental LNCaP cells (Fig. 5D and Supplementary Fig. 12A). This was unexpected because androgens increased total TBC1D4 and p-TBC1D4 levels (Fig. 5D) as well as glucose uptake (Fig. 5B) at this same time point. Taken together, androgen signaling may promote GLUT12 translocation to the PM through a CaMKK2-AMPK-TBC1D4-mediated mechanism but simultaneously cause its turnover at this same location through additional mechanisms that are unknown at this time.

\section{Discussion}

The data presented here suggest a working model, depicted in Fig. 6, for GLUT12 regulation in prostate cancer. SLC2A12, the gene encoding GLUT12, can directly be targeted by AR. This leads to a pulse of new GLUT12 synthesis. Simultaneously, androgens can directly increase the expression of CAMKK2 (Frigo et al. 2011). CaMKK2 can then later phosphorylate and activate the master metabolic regulator AMPK (Hawley et al. 2005, Hurley et al. 2005, Woods et al. 2005). Interestingly, as shown here in PC-3 cells (Supplementary Fig. 8) and by others in DU145 cells (Fu et al. 2015), CaMKK2-AMPK signaling is maintained in AR-negative prostate cancer cells, indicating that other transcription factors beyond AR promote CaMKK2-AMPK signaling. Regardless, CaMKK2-AMPK signaling will in turn increase GLUT12 translocation to the PM by modulating the activity, and to a lesser extent the expression, of TBC1D4, a known regulator of vesicle trafficking (Kramer et al. 2006, Treebak et al. 2006). Hence, we speculate that the initial pulse of GLUT12 synthesis following androgen treatment (with max levels achieved $\sim 24 \mathrm{~h}$ after treatment) provides new protein that can later be modified and/or translocated as a result of CaMKK2 signaling at a later time (ex. $72 \mathrm{~h}$ ). This newly modified/ translocated GLUT12 would then enable the turnover of older protein. In this regard, androgen signaling could serve to replenish the active levels of GLUT12 at the PM rather than simply increasing total GLUT12 levels throughout the cell. In addition to CaMKK2 signaling, our data (Figs 4 and 5, and Supplementary Figs 9 and 13) suggest that androgens may promote the expression of TBC1D4 through additional, CaMKK2-independent mechanisms (indicated in Fig. 6 as the expression of gene $X$, unknown at this time, that codes for protein $\mathrm{X}$ ). 
A
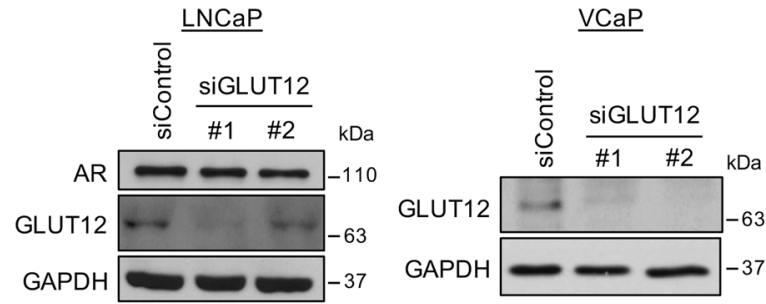

B

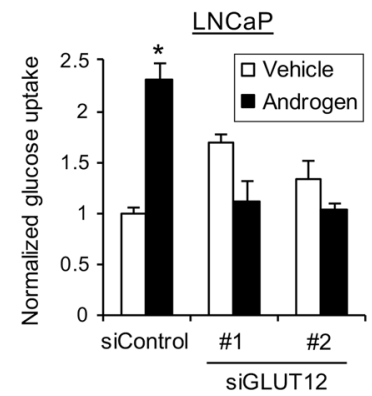

C

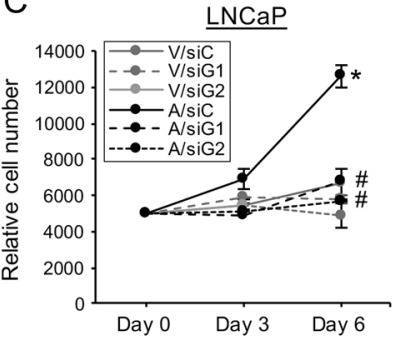

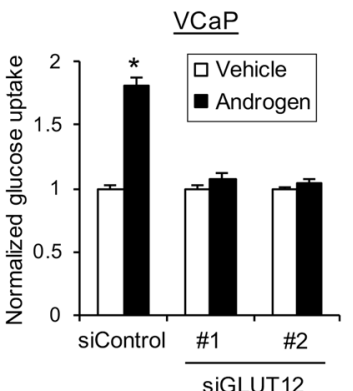

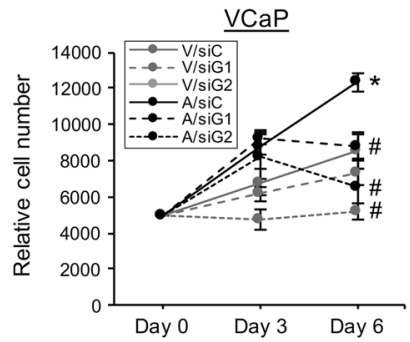

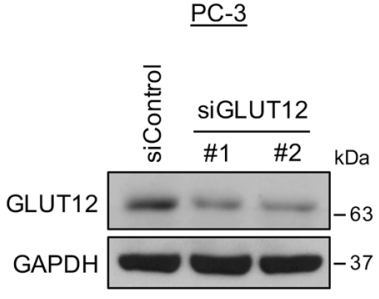
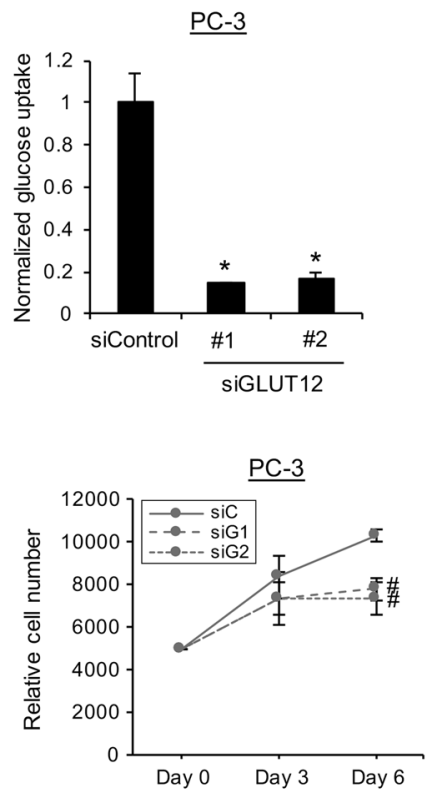
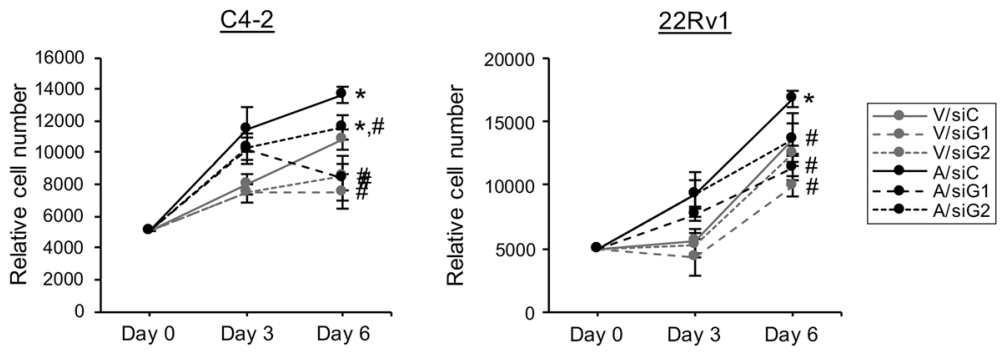

Figure 3

GLUT12 is required for maximal glucose uptake and cell growth in prostate cancer cells. (A) Indicated prostate cancer cells were transfected with siRNAs targeting a scramble sequence (siControl) or SLC2A12 (siGLUT12). After 72h, whole cell lysates were extracted and probed for GLUT12 and GAPDH (loading control) using Western blot analysis. (B) Indicated prostate cancer cells were transfected as in A. LNCaP or VCaP cells were also treated for $72 \mathrm{~h} \pm$ androgen (R1881). Glucose uptake was then measured using a bioanalyzer and data were normalized to cellular DNA content that was measured using a fluorescent DNA stain. *Significant $(P<0.05)$ changes from vehicle-treated (LNCaP and VCaP) or siControl (PC-3) cells. (C) Indicated prostate cancer cells were transfected with siRNAs targeting scramble control (siC) or SLC2A12 (siG1 and siG2) and/or treated with vehicle (V) or androgen (A) as in B for indicated time points. Relative cell numbers were then measured using the fluorescent DNA stain. *Significant $(P<0.05)$ changes from vehicletreated cells. \#Significant $(P<0.05)$ changes from siControl-transfected cells.

While the regulation of TBC1D4 by AMPK has been previously reported (Kramer et al. 2006, Treebak et al. 2006), to our knowledge, the androgen and CaMKK2AMPK modulation of TBC1D4 expression has not been previously described. Ultimately, this combined series of transcriptional and posttranscriptional events converge to increase the levels of functional GLUT12 at the PM where it can promote glucose uptake and subsequent cell growth.

GLUT12, as its name implies, was the 12th of 14 known glucose transporters of the SLC2A family to be identified (Rogers et al. 2002). As such, there is relatively 
A

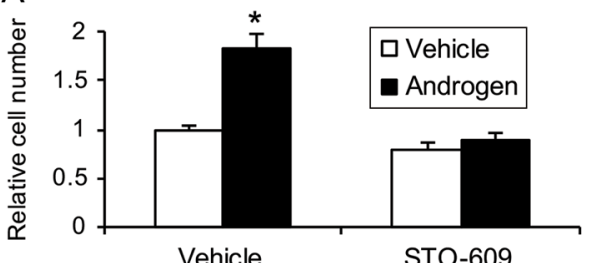

C Androgen: - - + +

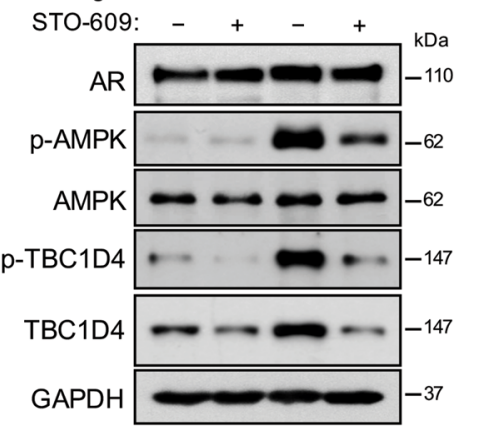

D

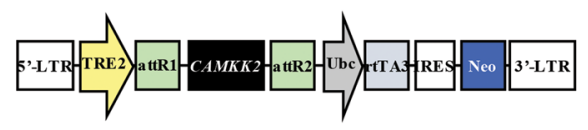

F

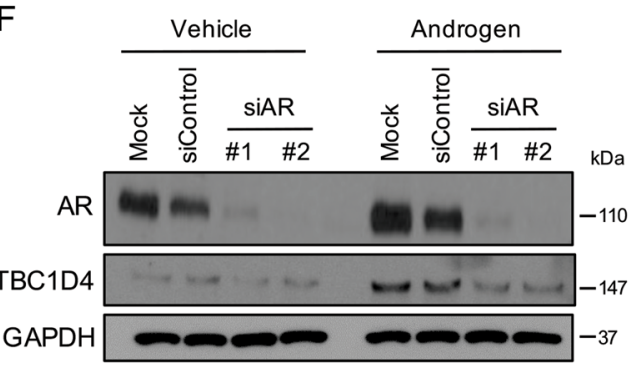

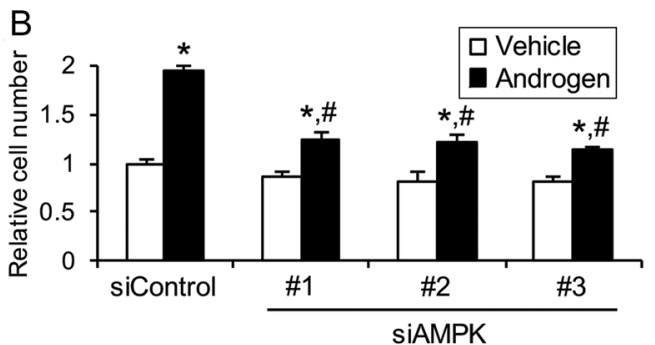

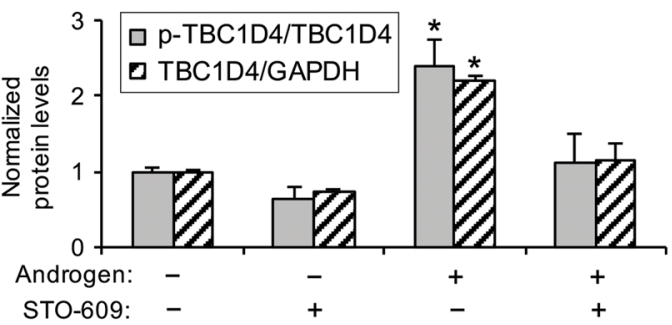

E Androgen (nM): - - - 0.110 Dox $(\mathrm{ng} / \mathrm{ml}):-\begin{array}{llllll}20 & 40 & 80 & - & - & k D a\end{array}$
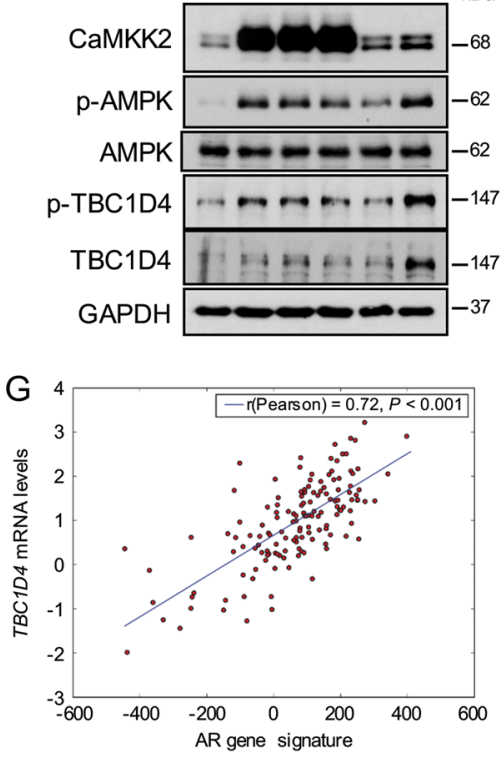

Figure 4

TBC1D4 is regulated by AR and CaMKK2-AMPK signaling. (A) LNCaP cells were co-treated $\pm 30 \mu \mathrm{M}$ STO-609 $\pm 10 \mathrm{nM}$ R1881 (androgen) for $72 \mathrm{~h}$. Relative cell numbers were then measured using a fluorescent DNA stain. *Significant $(P<0.05)$ changes from double vehicle-treated cells. (B) LNCaP cells were transfected with siRNAs targeting a scramble sequence (siControl) or AMPK and treated \pm androgen (R1881) for $72 \mathrm{~h}$. Relative cell numbers were then measured as in A. *Significant $(P<0.05)$ changes from vehicle treatment. "Significant $(P<0.05)$ changes from siControl. (C) LNCaP cells were treated for $72 \mathrm{~h} \pm$ STO-609 \pm androgen (R1881) after which whole cell lysates were analyzed via Western blot. Left, representative images. Right, Western blot analysis was subjected to densitometry. Total TBC1D4 levels were normalized to GAPDH levels and p-TBC1D4 levels were normalized to total TBC1D4 levels. *Significant $(P<0.05)$ changes from double vehicle-treated cells $(n=3)$. (D) Diagram of the construct used to create the LNCaP-CAMKK2 stable cell line in which CAMKK2 can be overexpressed in the presence of doxycycline. (E) LNCaP-CAMKK2 stable cells were treated for $72 \mathrm{~h}$ with increasing concentrations of doxycycline (Dox) or androgen (R1881). Whole-cell lysates were then analyzed via Western blot. (F) LNCaP cells were transfected with mock control or siRNAs targeting a scramble sequence (siControl) or $A R($ siAR) and treated \pm androgen (R1881) for $72 \mathrm{~h}$. Whole cell lysates were then analyzed via Western blot. (G) Expression of TBC1D4 correlated significantly with a previously described AR gene signature (Hieronymus et al. 2006) in transcriptomic profiles of prostate cancer patients from the Taylor et al. (2010) prostate cancer clinical cohort. Similar results were obtained using this AR activity signature as well as an additional AR activity signature (Nelson et al. 2002) across multiple clinical cohorts (Taylor et al. 2010, Grasso et al. 2012) including TCGA (Cerami et al. 2012). 
A
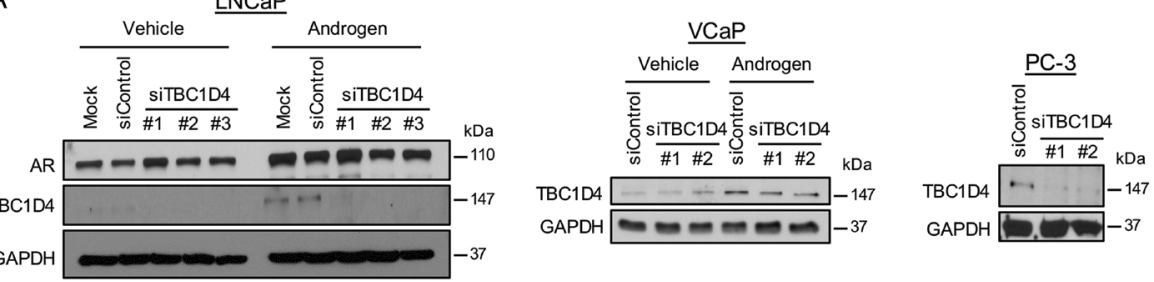

B

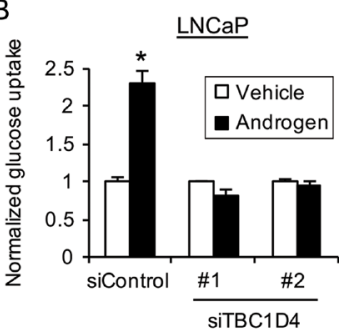

C

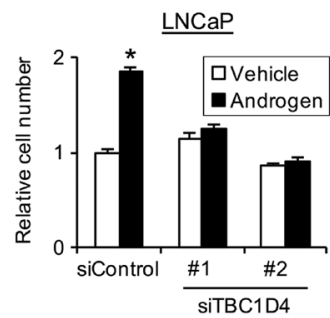

D

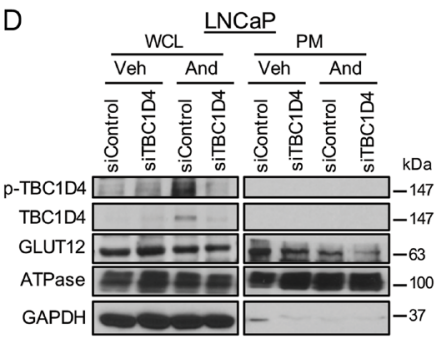

E

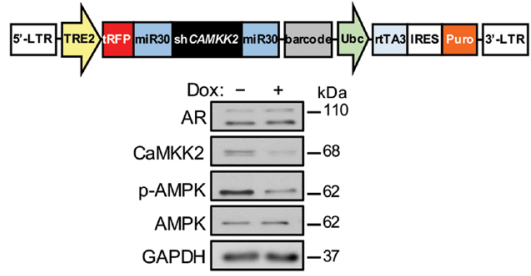

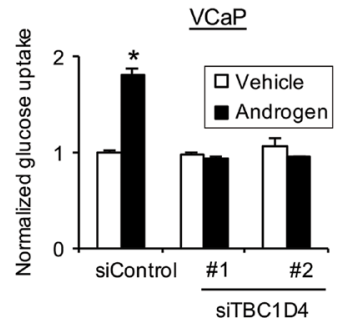
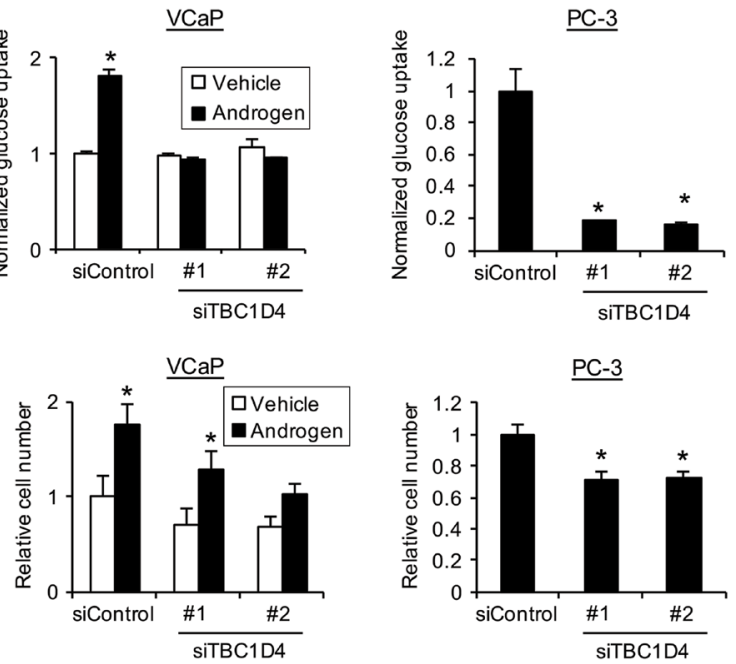

Figure 5

TBC1D4 regulates glucose uptake by modulating GLUT12 trafficking to the plasma membrane. (A) Indicated prostate cancer cells were transfected with mock or siRNAs targeting scramble control (siControl) or TBC1D4 (siTBC1D4). LNCaP or VCaP cells were also treated for 72h \pm androgen (10 nM R1881). Whole cell lysates were extracted and analyzed by Western blot. (B) Indicated prostate cancer cells were transfected and/or treated as in A. Glucose uptake was measured using a bioanalyzer, and data were normalized to cellular DNA content that was assessed using a fluorescent DNA stain

*Significant $(P<0.05)$ changes from vehicle-treated (LNCaP and VCaP) or siControl (PC-3) cells. (C) Indicated prostate cancer cells were transfected and/or treated as in B. Relative cell numbers were then measured using the fluorescent DNA stain. * Significant $(P<0.05)$ changes from vehicle-treated (LNCaP and VCaP) or siControl (PC-3) cells. (D) Indicated prostate cancer cells were transfected and/or treated as in A. Afterward, whole cell lysates (WCLs) were extracted and analyzed by Western blot. Duplicate cells were also subjected to a plasma membrane (PM) fractionation where the PM fraction was extracted and analyzed by Western blot. ATPase serves as a positive control for the enriched PM fraction. GAPDH serves as a loading control for the WCL. (E) Top, diagram of the construct used to create the 22Rv1-shCAMKK2 stable cell line in which shRNA targeting CAMKK2 can be overexpressed in the presence of doxycycline. Bottom, Western blot validation of the 22Rv1-shCAMKK2 stable cell line. 22Rv1-shCAMKK2 stable cells were treated for $72 \mathrm{~h} \pm 800 \mathrm{ng} / \mathrm{mL}$ doxycycline (Dox). Whole cell lysates were then analyzed via Western blot. (F) 22Rv1-shCAMKK2 cells were treated the same as in $\mathrm{E}$ and then subjected to fractionation and Western blot analysis as described in D. 
little known about its regulation and function compared to many other GLUTs such as GLUT1 and GLUT4. Interestingly, GLUT12 was first discovered in MCF-7 breast cancer cells (Rogers et al. 2002). Since then, it has been found to be expressed in a number of malignancies including rhabdomyosarcomas, oligodendrogliomas, oligoastrocytomas, astrocytomas as well as breast, lung, colorectal and prostate cancers (Rogers et al. 2002, 2003, Chandler et al. 2003, Stockhammer et al. 2008, Pujol-Gimenez et al. 2015). Hence, a potential oncogenic role for this transporter has been emerging. In agreement with the mRNA expression data listed in Table 1, immunohistochemical staining for GLUT12 revealed the transporter's protein expression in malignant but not benign prostatic hyperplasia tissue (Chandler et al. 2003). In estrogen receptor-positive (ER+) MCF-7 breast cancer cells, 24-h treatment with the steroid hormone estrogen was shown to increase GLUT12 protein but not mRNA levels, suggesting estrogen increased GLUT12 levels by promoting translation or protein stability (Macheda et al. 2005). They also demonstrated that GLUT12 protein could not be detected in ER-negative breast cancer cells, further supporting a model of ER regulation. The authors additionally stated (but did not show the data) that 24-h DHT treatment increased GLUT12 protein levels in MCF-7 cells, which express AR (Macheda et al. 2005). It was not reported whether DHT increased mRNA expression. Like ER signaling in breast cancer cells, our data demonstrate that AR signaling increased GLUT12 expression in prostate cancer (Figs 1, 2 and Supplementary Figs 1, 4, 5 and 6). However, our findings indicate that, unlike ER signaling in breast cancer, SLC2A12 is a direct AR target in prostate cancer cells (Fig. 2 and Supplementary Figs 5 and 6). Further, AR-negative PC-3 prostate cancer cells express GLUT12, indicating that AR is not the only transcription factor that regulates $S L C 2 A 12$ (Figs 3 and 5 and Supplementary Figs 2 and 12).

GLUT transporters are grouped into three classes based on their sequence homology and structure (Joost \& Thorens 2001, Barron et al. 2016). GLUT12 belongs to class III while many of the originally identified GLUTs including the insulin-regulated GLUT4 belong to class I. Despite belonging to two different classes, GLUT12 was originally identified by homology to GLUT4 (Rogers et al. 2002). Like GLUT4, evidence suggests that GLUT12's subcellular location is also regulated by signals such as insulin (Rogers et al. 2002, Stuart et al. 2009). In this regard, it is of note that GLUT12 possesses the motifs found in GLUT4 that facilitate this transporter's subcellular trafficking (Rogers et al. 2002). To that end,

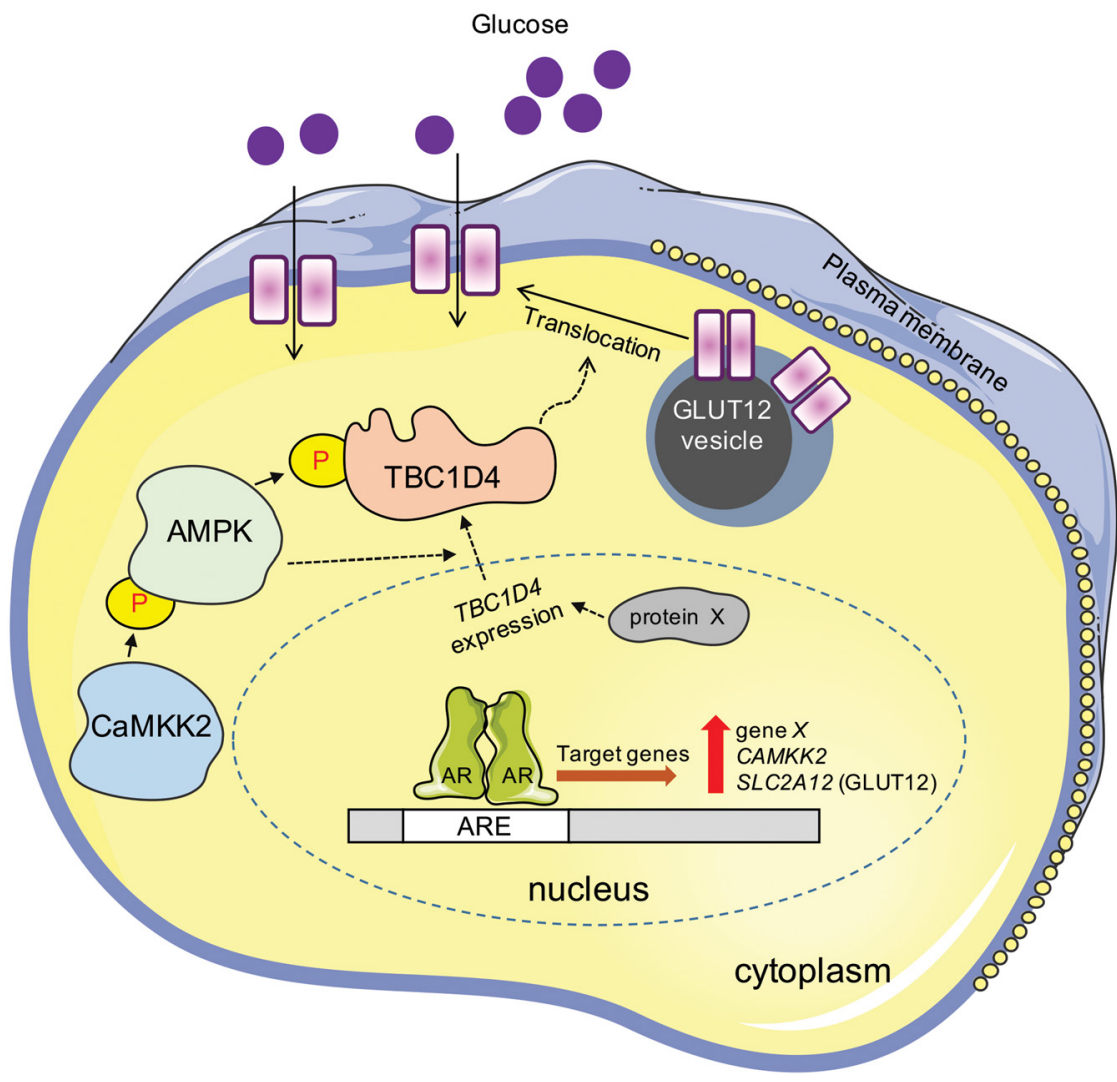

Figure 6

Working model of GLUT12 regulation and function in prostate cancer. AR directly increases the expression of CAMKK2, SLC2A12 (GLUT12), and an additional gene, $X$, unknown at this time. CaMKK2 signaling also promotes GLUT12 function through the AMPK-mediated phosphorylation of TBC1D4, promoting GLUT12 translocation to the plasma membrane through a posttranslational mechanism similar to that described for GLUT4. Interestingly, CaMKK2 signaling also appears to modulate GLUT12 translocation by regulating the posttranscriptional expression of TBC1D4 through a still poorly defined mechanism (indicated by the dashed lines). Further, AR can increase TBC1D4 expression in a CaMKK2-independent manner (indicated by the expression of gene $X$ that codes for protein $\mathrm{X}$ ). Together, these combined events ultimately function to increase the level of plasma membrane-localized GLUT12 and therefore promote cellular glucose uptake and subsequent metabolism. http://erc.endocrinology-journals.org https://doi.org/10.1530/ERC-17-0051

\section{() 2018 Society for Endocrinology Published by Bioscientifica Ltd.} Printed in Great Britain 
it has been speculated that GLUT4 and GLUT12 might even be colocalized to the same vesicles under baseline conditions. Our data here suggest that like GLUT4 (Sano et al. 2003, Miinea et al. 2005), GLUT12 translocation is also regulated by TBC1D4 (Fig. 5).

Under physiological conditions in muscle or fat, TBC1D4 can be phosphorylated by Akt or AMPK (Miinea et al. 2005, Sakamoto \& Holman 2008, Stuart et al. 2009, Cartee 2015). This phosphorylation inhibits its Rab GTPase-activating activity and promotes GLUT4 and, as our data suggest here, GLUT12 translocation. Consistent with this, inhibition of CaMKK2-AMPK kinase signaling by STO-609 or shRNA-mediated silencing of CAMKK2 decreased GLUT12 PM levels (Fig. 5 and Supplementary Fig. 12) and glucose uptake (Massie et al. 2011). The existence of this regulatory mechanism for GLUT12 is consistent with the presence of the conserved motif, described earlier, in both transporters that are known to be responsible for insulin-mediated GLUT4 translocation. As this phosphorylation is an inhibitory event, it is not unexpected that knockdown of TBC1D4 or its paralog $T B C 1 D 1$ have been described before to increase cell surface GLUT4 levels and glucose uptake in muscle and fat cells (Eguez et al. 2005, Sano et al. 2007, Chavez et al. 2008). Paradoxically, silencing of TBC1D4 in prostate cancer cells decreased the plasma membrane-localized levels of GLUT12 while having no effect on total GLUT12 levels (Fig. 5D). These findings suggest that TBC1D4 might be required to establish basal GLUT12 vesicle trafficking that can then be further regulated in response to cues such as CaMKK2 signaling. Future experiments will be critical to determine whether this regulation is specific to GLUT12 and/or prostate cancer.

At this time, we cannot exclude the possibility that androgens or CaMKK2-AMPK signaling could promote glucose uptake through additional, GLUT12-independent mechanisms. As described earlier, TBC1D4 was first demonstrated to regulate the translocation of GLUT4 (Kramer et al. 2006, Treebak et al. 2006), a transporter that is also expressed (albeit lower) in the prostate (Fig. 1) (Gonzalez-Menendez et al. 2014). In addition, AMPK has been reported to increase GLUT1 levels through a variety of mechanisms (Barnes et al. 2002, Wu et al. 2013). Further, AMPK can directly phosphorylate two of the four isoenzymes of 6-phosphofructo-2-kinase/fructose-2, 6-bisphosphate 2-phosphatase (PFKFB), an enzyme that represents the rate-limiting step of glycolysis (Marsin et al. 2000, Almeida et al. 2004, Domenech et al. 2015). These phosphorylation events on PFKFB2 and PFKFB3 increase their kinase activity and, therefore, promote forward flux through glycolysis. Because glucose uptake through the facilitative transporters is regulated by the concentration gradient, increased cellular catabolism of glucose would stimulate the uptake of more sugar by other GLUTs that might also function independently of TBC1D4. Likewise, androgens and CaMKK2-AMPK signaling have also been demonstrated to increase glucose metabolism through the tricarboxylic acid (TCA) cycle, the hexosamine biosynthetic pathway and the pentose phosphate pathway (Massie et al. 2011, Itkonen et al. 2013, Tennakoon et al. 2014, Tsouko et al. 2014). Collectively, these effects suggest that GLUT12 represents only one of potentially several mechanisms downstream of androgen and CaMKK2 signaling that could increase glucose uptake. Given prostate cancer's heterogeneous makeup (Cancer Genome Atlas Research 2015), it is likely that some subtypes may favor GLUT12- and/or TBC1D4-independent glucose uptake.

This study examined the regulation and role of the transporter GLUT12 in glucose uptake. It still remains to be determined how glucose is then used by the cancer cells. As described earlier, androgen and CaMKK2 signaling have previously been demonstrated to promote glucose metabolism through the hexosamine biosynthetic pathway, the pentose phosphate pathway, glycolysis and the TCA cycle in prostate cancer (Massie et al. 2011, Itkonen et al. 2013, Tennakoon et al. 2014, Tsouko et al. 2014). In addition, androgens are known to stimulate the formation of intracellular fat depots, thought to promote growth, in prostate cancer cells (Swinnen et al. 2006, Shi et al. 2013). These fat reservoirs are likely created in part through the breakdown of sugars and shuttling of their carbons into de novo lipogenesis. Future studies using isotopic tracing techniques will undoubtedly help determine the exact contribution of each one of these pathways to the growing tumor.

\section{Supplementary data}

This is linked to the online version of the paper at https://doi.org/10.1530/ ERC-17-0051.

Declaration of interest

The authors declare that there is no conflict of interest that could be perceived as prejudicing the impartiality of the research reported.

\section{Funding}

This study was supported by NIH grant R01CA184208 (D E F). This work was also partially supported by a CPRIT Proteomics and Metabolomics Core Facility Support Award RP170005 (C C and K R). 


\section{Acknowledgements}

The authors thank members of the Frigo Laboratory for their technical support, critical reading of the manuscript and their suggestions. They also thank Thomas Westbrook (Baylor College of Medicine) for the pINDUCER constructs, Zhang Weihua (University of Houston) for the use of his bioanalyzer and Servier Medical Art for providing background images that were used in the creation of Fig. 6 .

\section{References}

Almeida A, Moncada S \& Bolanos JP 2004 Nitric oxide switches on glycolysis through the AMP protein kinase and 6-phosphofructo-2kinase pathway. Nature Cell Biology 6 45-51. (https://doi.org/10.1038/ ncb1080)

American Cancer Society 2015 Cancer Facts \& Figures 2015. Atlanta, GA, USA: American Cancer Society. (available at: https://www.cancer.org/ research/cancer-facts-statistics/all-cancer-facts-figures/cancer-factsfigures-2015.html)

Barnes K, Ingram JC, Porras OH, Barros LF, Hudson ER, Fryer LG, Foufelle F, Carling D, Hardie DG \& Baldwin SA 2002 Activation of GLUT1 by metabolic and osmotic stress: potential involvement of AMP-activated protein kinase (AMPK). Journal of Cell Science $\mathbf{1 1 5}$ 2433-2442.

Barron CC, Bilan PJ, Tsakiridis T \& Tsiani E 2016 Facilitative glucose transporters: implications for cancer detection, prognosis and treatment. Metabolism 65 124-139. (https://doi.org/10.1016/j. metabol.2015.10.007)

Blessing AM, Ganesan S, Rajapakshe K, Ying Sung Y, Reddy Bollu L, Shi Y, Cheung E, Coarfa C, Chang JT, McDonnell DP, et al. 2015 Identification of a novel coregulator, SH3YL1, that interacts with the androgen receptor N-terminus. Molecular Endocrinology 29 1426-1439. (https://doi.org/10.1210/me.2015-1079)

Blessing AM, Rajapakshe K, Reddy Bollu L, Shi Y, White MA, Pham AH, Lin C, Jonsson P, Cortes CJ, Cheung E, et al. 2017 Transcriptional regulation of core autophagy and lysosomal genes by the androgen receptor promotes prostate cancer progression. Autophagy $\mathbf{1 3}$ 506-521. (https://doi.org/10.1080/15548627.2016.1268300)

Cairns RA, Harris IS \& Mak TW 2011 Regulation of cancer cell metabolism. Nature Reviews Cancer 11 85-95. (https://doi. org $/ 10.1038 /$ nrc2981)

Cancer Genome Atlas Research Network 2015 The molecular taxonomy of primary prostate cancer. Cell 163 1011-1025. (https://doi. org/10.1016/j.cell.2015.10.025)

Cartee GD 2015 AMPK-TBC1D4-dependent mechanism for increasing insulin sensitivity of skeletal muscle. Diabetes 64 1901-1903. (https://doi.org/10.2337/db15-0010)

Cerami E, Gao J, Dogrusoz U, Gross BE, Sumer SO, Aksoy BA, Jacobsen A, Byrne CJ, Heuer ML, Larsson E, et al. 2012 The cBio cancer genomics portal: an open platform for exploring multidimensional cancer genomics data. Cancer Discovery 2 401-404. (https://doi.org/10.1158/2159-8290.CD-12-0095)

Chandler JD, Williams ED, Slavin JL, Best JD \& Rogers S 2003 Expression and localization of GLUT1 and GLUT12 in prostate carcinoma. Cancer 97 2035-2042. (https://doi.org/10.1002/cncr.11293)

Chavez JA, Roach WG, Keller SR, Lane WS \& Lienhard GE 2008 Inhibition of GLUT4 translocation by Tbc1d1, a Rab GTPaseactivating protein abundant in skeletal muscle, is partially relieved by AMP-activated protein kinase activation. Journal of Biological Chemistry 283 9187-9195. (https://doi.org/10.1074/jbc. M708934200)

Chng KR, Chang CW, Tan SK, Yang C, Hong SZ, Sng NY \& Cheung E 2012 A transcriptional repressor co-regulatory network governing androgen response in prostate cancers. EMBO Journal 31 2810-2823. (https://doi.org/10.1038/emboj.2012.112)

Domenech E, Maestre C, Esteban-Martinez L, Partida D, Pascual R, Fernandez-Miranda G, Seco E, Campos-Olivas R, Perez M, Megias D, et al. 2015 AMPK and PFKFB3 mediate glycolysis and survival in response to mitophagy during mitotic arrest. Nature Cell Biology $\mathbf{1 7}$ 1304-1316. (https://doi.org/10.1038/ncb3231)

Eguez L, Lee A, Chavez JA, Miinea CP, Kane S, Lienhard GE \& McGraw TE 2005 Full intracellular retention of GLUT4 requires AS160 Rab GTPase activating protein. Cell Metabolism 2 263-272. (https://doi.org/10.1016/j.cmet.2005.09.005)

Frigo DE, Sherk AB, Wittmann BM, Norris JD, Wang Q, Joseph JD, Toner AP, Brown M \& McDonnell DP 2009 Induction of Kruppel-like factor 5 expression by androgens results in increased CXCR4dependent migration of prostate cancer cells in vitro. Molecular Endocrinology 23 1385-1396. (https://doi.org/10.1210/me.2009-0010)

Frigo DE, Howe MK, Wittmann BM, Brunner AM, Cushman I, Wang Q, Brown M, Means AR \& McDonnell DP 2011 CaM kinase kinase betamediated activation of the growth regulatory kinase AMPK is required for androgen-dependent migration of prostate cancer cells Cancer Research 71 528-537. (https://doi.org/10.1158/0008-5472. CAN-10-2581)

Fu H, He HC, Han ZD, Wan YP, Luo HW, Huang YQ, Cai C, Liang YX, Dai QS, Jiang FN, et al. 2015 MicroRNA-224 and its target CAMKK2 synergistically influence tumor progression and patient prognosis in prostate cancer. Tumour Biology 36 1983-1991. (https://doi. org/10.1007/s13277-014-2805-0)

Gonzalez-Menendez P, Hevia D, Rodriguez-Garcia A, Mayo JC \& Sainz RM 2014 Regulation of GLUT transporters by flavonoids in androgen-sensitive and -insensitive prostate cancer cells. Endocrinology 155 3238-3250. (https://doi.org/10.1210/en.2014-1260)

Grasso CS, Wu YM, Robinson DR, Cao X, Dhanasekaran SM, Khan AP, Quist MJ, Jing X, Lonigro RJ, Brenner JC, et al. 2012 The mutational landscape of lethal castration-resistant prostate cancer. Nature $\mathbf{4 8 7}$ 239-243. (https://doi.org/10.1038/nature11125)

Hanahan D \& Weinberg RA 2011 Hallmarks of cancer: the next generation. Cell 144 646-674. (https://doi.org/10.1016/j. cell.2011.02.013)

Hatanaka M 1974 Transport of sugars in tumor cell membranes. Biochimica et Biophysica Acta 355 77-104. (https://doi. org/10.1016/0304-419X(74)90008-0)

Hawley SA, Pan DA, Mustard KJ, Ross L, Bain J, Edelman AM, Frenguelli BG \& Hardie DG 2005 Calmodulin-dependent protein kinase kinase-beta is an alternative upstream kinase for AMPactivated protein kinase. Cell Metabolism 2 9-19. (https://doi. org/10.1016/j.cmet.2005.05.009)

Hieronymus $\mathrm{H}$, Lamb J, Ross KN, Peng XP, Clement C, Rodina A, Nieto M, Du J, Stegmaier K, Raj SM, et al. 2006 Gene expression signature-based chemical genomic prediction identifies a novel class of HSP90 pathway modulators. Cancer Cell 10 321-330. (https://doi. org/10.1016/j.ccr.2006.09.005)

Hurley RL, Anderson KA, Franzone JM, Kemp BE, Means AR \& Witters LA 2005 The Ca2+/calmodulin-dependent protein kinase kinases are AMP-activated protein kinase kinases. Journal of Biological Chemistry 280 29060-29066. (https://doi.org/10.1074/jbc. M503824200)

Itkonen HM, Minner S, Guldvik IJ, Sandmann MJ, Tsourlakis MC, Berge V, Svindland A, Schlomm T \& Mills IG 2013 O-GlcNAc transferase integrates metabolic pathways to regulate the stability of c-MYC in human prostate cancer cells. Cancer Research $\mathbf{7 3}$ 5277-5287. (https://doi.org/10.1158/0008-5472.CAN-13-0549)

Joost HG \& Thorens B 2001 The extended GLUT-family of sugar/polyol transport facilitators: nomenclature, sequence characteristics, and potential function of its novel members. Molecular Membrane Biology 18 247-256. (https://doi.org/10.1080/09687680110090456) (c) 2018 Society for Endocrinology Published by Bioscientifica Ltd. Printed in Great Britain 
Jurmeister S, Ramos-Montoya A, Neal DE \& Fryer LG 2014 Transcriptomic analysis reveals inhibition of androgen receptor activity by AMPK in prostate cancer cells. Oncotarget 5 3785-3799. (https://doi.org/10.18632/oncotarget.1997)

Karacosta LG, Foster BA, Azabdaftari G, Feliciano DM \& Edelman AM 2012 A regulatory feedback loop between $\mathrm{Ca} 2+/$ calmodulindependent protein kinase kinase 2 (CaMKK2) and the androgen receptor in prostate cancer progression. Journal of Biological Chemistry 287 24832-24843. (https://doi.org/10.1074/jbc. M112.370783)

Karacosta LG, Kuroski LA, Hofmann WA, Azabdaftari G, Mastri M, Gocher AM, Dai S, Hoste AJ \& Edelman AM 2016 Nucleoporin 62 and $\mathrm{Ca}(2+) /$ calmodulin dependent kinase kinase 2 regulate androgen receptor activity in castrate resistant prostate cancer cells. Prostate 76 294-306. (https://doi.org/10.1002/pros.23121)

Kramer HF, Witczak CA, Fujii N, Jessen N, Taylor EB, Arnolds DE, Sakamoto K, Hirshman MF \& Goodyear LJ 2006 Distinct signals regulate AS160 phosphorylation in response to insulin, AICAR, and contraction in mouse skeletal muscle. Diabetes 55 2067-2076. (https://doi.org/10.2337/db06-0150)

Labak CM, Wang PY, Arora R, Guda MR, Asuthkar S, Tsung AJ \& Velpula KK 2016 Glucose transport: meeting the metabolic demands of cancer, and applications in glioblastoma treatment. American Journal of Cancer Research 6 1599-1608.

Luiken JJ, Glatz JF \& Neumann D 2015 Cardiac contraction-induced GLUT4 translocation requires dual signaling input. Trends in Endocrinology and Metabolism 26 404-410. (https://doi.org/10.1016/j. tem.2015.06.002)

Luo JH, Yu YP, Cieply K, Lin F, Deflavia P, Dhir R, Finkelstein S, Michalopoulos G \& Becich M 2002 Gene expression analysis of prostate cancers. Molecular Carcinogenesis 33 25-35. (https://doi. org/10.1002/mc.10018)

Macheda ML, Rogers S \& Best JD 2005 Molecular and cellular regulation of glucose transporter (GLUT) proteins in cancer. Journal of Cellular Physiology 202 654-662. (https://doi.org/10.1002/jcp.20166)

Marsin AS, Bertrand L, Rider MH, Deprez J, Beauloye C, Vincent MF, Van den Berghe G, Carling D \& Hue L 2000 Phosphorylation and activation of heart PFK-2 by AMPK has a role in the stimulation of glycolysis during ischaemia. Current Biology 10 1247-1255. (https:// doi.org/10.1016/S0960-9822(00)00742-9)

Massie CE, Lynch A, Ramos-Montoya A, Boren J, Stark R, Fazli L, Warren A, Scott H, Madhu B, Sharma N, et al. 2011 The androgen receptor fuels prostate cancer by regulating central metabolism and biosynthesis. EMBO Journal 30 2719-2733. (https://doi.org/10.1038/ emboj.2011.158)

Miinea CP, Sano H, Kane S, Sano E, Fukuda M, Peranen J, Lane WS \& Lienhard GE 2005 AS160, the Akt substrate regulating GLUT4 translocation, has a functional Rab GTPase-activating protein domain. Biochemical Journal 391 87-93. (https://doi.org/10.1042/ BJ20050887)

Miyamoto T, Rho E, Sample V, Akano H, Magari M, Ueno T, Gorshkov K, Chen M, Tokumitsu H, Zhang J, et al. 2015 Compartmentalized AMPK signaling illuminated by genetically encoded molecular sensors and actuators. Cell Reports 11 657-670. (https://doi. org/10.1016/j.celrep.2015.03.057)

Moon JS, Jin WJ, Kwak JH, Kim HJ, Yun MJ, Kim JW, Park SW \& Kim KS 2011 Androgen stimulates glycolysis for de novo lipid synthesis by increasing the activities of hexokinase 2 and 6-phosphofructo-2kinase/fructose-2,6-bisphosphatase 2 in prostate cancer cells. Biochemical Journal 433 225-233. (https://doi.org/10.1042/ BJ20101104)

Nelson PS, Clegg N, Arnold H, Ferguson C, Bonham M, White J, Hood L \& Lin B 2002 The program of androgen-responsive genes in neoplastic prostate epithelium. PNAS 99 11890-11895. (https://doi. org/10.1073/pnas.182376299)
Pujol-Gimenez J, de Heredia FP, Idoate MA, Airley R, Lostao MP \& Evans AR 2015 Could GLUT12 be a potential therapeutic target in cancer treatment? A preliminary report. Journal of Cancer 6 139-143. (https://doi.org/10.7150/jca.10429)

Rogers S, Macheda ML, Docherty SE, Carty MD, Henderson MA, Soeller WC, Gibbs EM, James DE \& Best JD 2002 Identification of a novel glucose transporter-like protein-GLUT-12. American Journal of Physiology: Endocrinology and Metabolism 282 E733-E738. (https://doi. org/10.1152/ajpendo.2002.282.3.E733)

Rogers S, Docherty SE, Slavin JL, Henderson MA \& Best JD 2003 Differential expression of GLUT12 in breast cancer and normal breast tissue. Cancer Letters 193 225-233. (https://doi.org/10.1016/ S0304-3835(03)00010-7)

Sakamoto K \& Holman GD 2008 Emerging role for AS160/TBC1D4 and TBC1D1 in the regulation of GLUT4 traffic. American Journal of Physiology: Endocrinology and Metabolism 295 E29-E37. (https://doi. org/10.1152/ajpendo.90331.2008)

Sano H, Kane S, Sano E, Miinea CP, Asara JM, Lane WS, Garner CW \& Lienhard GE 2003 Insulin-stimulated phosphorylation of a Rab GTPase-activating protein regulates GLUT4 translocation. Journal of Biological Chemistry 278 14599-14602. (https://doi.org/10.1074/jbc. C300063200)

Sano H, Eguez L, Teruel MN, Fukuda M, Chuang TD, Chavez JA, Lienhard GE \& McGraw TE 2007 Rab10, a target of the AS160 Rab GAP, is required for insulin-stimulated translocation of GLUT4 to the adipocyte plasma membrane. Cell Metabolism 5 293-303. (https:// doi.org/10.1016/j.cmet.2007.03.001)

Schmidt LJ \& Tindall DJ 2013 Androgen receptor: past, present and future. Current Drug Targets 14 401-407. (https://doi.org/10.2174/138 9450111314040002)

Seidler NW 2013 Compartmentation of GAPDH. Advances in Experimental Medicine and Biology 985 61-101.

Shen M, Zhang Z, Ratnam M \& Dou QP 2014 The interplay of AMPactivated protein kinase and androgen receptor in prostate cancer cells. Journal of Cellular Physiology 229 688-695. (https://doi. $\operatorname{org} / 10.1002 /$ jcp.24494)

Shi Y, Han JJ, Tennakoon JB, Mehta FF, Merchant FA, Burns AR, Howe MK, McDonnell DP \& Frigo DE 2013 Androgens promote prostate cancer cell growth through induction of autophagy. Molecular Endocrinology 27 280-295. (https://doi.org/10.1210/ me.2012-1260)

Simpson IA, Dwyer D, Malide D, Moley KH, Travis A \& Vannucci SJ 2008 The facilitative glucose transporter GLUT3: 20 years of distinction. American Journal of Physiology: Endocrinology and Metabolism 295 E242-E253. (https://doi.org/10.1152/ ajpendo.90388.2008)

Sirover MA 2012 Subcellular dynamics of multifunctional protein regulation: mechanisms of GAPDH intracellular translocation. Journal of Cellular Biochemistry 113 2193-2200. (https://doi. org/10.1002/jcb.24113)

Stockhammer F, von Deimling A, Synowitz M, Blechschmidt C \& van Landeghem FK 2008 Expression of glucose transporter 1 is associated with loss of heterozygosity of chromosome $1 \mathrm{p}$ in oligodendroglial tumors WHO grade II. Journal of Molecular Histology 39 553-560. (https://doi.org/10.1007/s10735-008-9191-0)

Stuart CA, Howell ME, Zhang Y \& Yin D 2009 Insulin-stimulated translocation of glucose transporter (GLUT) 12 parallels that of GLUT4 in normal muscle. Journal of Clinical Endocrinology and Metabolism 94 3535-3542. (https://doi.org/10.1210/jc.2009-0162)

Swinnen JV, Brusselmans K \& Verhoeven G 2006 Increased lipogenesis in cancer cells: new players, novel targets. Current Opinion in Clinical Nutrition and Metabolic Care 9 358-365. (https://doi.org/10.1097/01. mco.0000232894.28674.30)

Tan PY, Chang CW, Chng KR, Wansa KD, Sung WK \& Cheung E 2012 Integration of regulatory networks by NKX3-1 promotes androgen-
(C) 2018 Society for Endocrinology Published by Bioscientifica Ltd. Printed in Great Britain 
dependent prostate cancer survival. Molecular and Cellular Biology 32 399-414. (https://doi.org/10.1128/MCB.05958-11)

Taylor BS, Schultz N, Hieronymus H, Gopalan A, Xiao Y, Carver BS, Arora VK, Kaushik P, Cerami E, Reva B, et al. 2010 Integrative genomic profiling of human prostate cancer. Cancer Cell 18 11-22. (https://doi.org/10.1016/j.ccr.2010.05.026)

Tennakoon JB, Shi Y, Han JJ, Tsouko E, White MA, Burns AR, Zhang A, Xia X, Ilkayeva OR, Xin L, et al. 2014 Androgens regulate prostate cancer cell growth via an AMPK-PGC-1alpha-mediated metabolic switch. Oncogene 33 5251-5261. (https://doi.org/10.1038/onc.2013.463)

Treebak JT, Glund S, Deshmukh A, Klein DK, Long YC, Jensen TE, Jorgensen SB, Viollet B, Andersson L, Neumann D, et al. 2006 AMPKmediated AS160 phosphorylation in skeletal muscle is dependent on AMPK catalytic and regulatory subunits. Diabetes 55 2051-2058. (https://doi.org/10.2337/db06-0175)

Tsouko E, Khan AS, White MA, Han JJ, Shi Y, Merchant FA, Sharpe MA, Xin L \& Frigo DE 2014 Regulation of the pentose phosphate pathway by an androgen receptor-mTOR-mediated mechanism and its role in prostate cancer cell growth. Oncogenesis 3 e103. (https:// doi.org/10.1038/oncsis.2014.18)

Vanaja DK, Cheville JC, Iturria SJ \& Young CY 2003 Transcriptional silencing of zinc finger protein 185 identified by expression profiling is associated with prostate cancer progression. Cancer Research 63 $3877-3882$.
Varambally S, Yu J, Laxman B, Rhodes DR, Mehra R, Tomlins SA, Shah RB, Chandran U, Monzon FA, Becich MJ, et al. 2005 Integrative genomic and proteomic analysis of prostate cancer reveals signatures of metastatic progression. Cancer Cell 8 393-406. (https://doi. org/10.1016/j.ccr.2005.10.001)

Wallace TA, Prueitt RL, Yi M, Howe TM, Gillespie JW, Yfantis HG, Stephens RM, Caporaso NE, Loffredo CA \& Ambs S 2008 Tumor immunobiological differences in prostate cancer between AfricanAmerican and European-American men. Cancer Research 68 927-936. (https://doi.org/10.1158/0008-5472.CAN-07-2608)

Welsh JB, Sapinoso LM, Su AI, Kern SG, Wang-Rodriguez J, Moskaluk CA, Frierson HF Jr \& Hampton GM 2001 Analysis of gene expression identifies candidate markers and pharmacological targets in prostate cancer. Cancer Research 61 5974-5978.

Woods A, Dickerson K, Heath R, Hong SP, Momcilovic M, Johnstone SR, Carlson M \& Carling D 2005 Ca2+/calmodulin-dependent protein kinase kinase-beta acts upstream of AMP-activated protein kinase in mammalian cells. Cell Metabolism 2 21-33. (https://doi.org/10.1016/j. cmet.2005.06.005)

Wu N, Zheng B, Shaywitz A, Dagon Y, Tower C, Bellinger G, Shen CH, Wen J, Asara J, McGraw TE, et al. 2013 AMPK-dependent degradation of TXNIP upon energy stress leads to enhanced glucose uptake via GLUT1. Molecular Cell 49 1167-1175. (https://doi.org/10.1016/j. molcel.2013.01.035)

Received in final form 29 January 2018

Accepted 5 February 2018

Accepted Preprint published online 5 February 2018
(C) 2018 Society for Endocrinology Published by Bioscientifica Ltd. Printed in Great Britain 